\title{
Sodium Channels from Human Brain RNA Expressed in Xenopus Oocytes Basic Electrophysiologic Characteristics and Their Modification by Diphenylhydantoin
}

Gordon F. Tomaselli,* Eduardo Marban, * and Gary Yellen

*Department of Medicine, Division of Cardiology, The Johns Hopkins School of Medicine; ${ }^{\ddagger}$ Department of Neuroscience and

The Howard Hughes Medical Institute, The Johns Hopkins School of Medicine, Baltimore, Maryland 21205

\begin{abstract}
We describe the expression and characterization of sodium channels from human brain RNA in the Xenopus oocyte. The expressed channel, studied by whole-cell voltage clamp, reveals characteristic selectivity for sodium as the permeant ion, voltage-dependent gating, and block by nanomolar concentrations of tetrodotoxin. Such channels are not seen in control oocytes injected with solvent only. The anticonvulsant diphenylhydantoin (DPH) inhibits the expressed channel in a voltage- and use-dependent manner, much like the effect seen in primary mammalian neuronal preparations. The inhibition of the expressed human sodium channel by DPH can be described by models previously developed to explain block of $\mathrm{Na}$ channels by local anesthetics. The preferential block of $\mathrm{Na}$ channels during depolarization helps explain the selectivity of DPH for neurons involved in seizure activity.
\end{abstract}

\section{Introduction}

Neurochemical and electrophysiologic studies of the anticonvulsant diphenylhydantoin (DPH) ${ }^{1}$ have revealed a multitude of effects of the drug on excitable tissue (1-10). Based on studies of the effect of DPH on inward sodium currents (1-6) and the characteristics of experimental epileptogenesis (11), $\mathrm{Na}$ channel inhibition is considered central to the mechanism of its anticonvulsant activity. In mammalian neuronal preparations, DPH has been shown to block the binding of sodium channel activators such as batrachotoxin and to inhibit the persistent activation of sodium channels by these substances $(12,13)$. At therapeutic concentrations $(5-10 \mu \mathrm{M})$, DPH does not generally inhibit $\mathrm{Na}$ channels, which would be expected to cause sedation, but does inhibit channels that are depolarized at rest or that fire frequently $(3,4)$. Neurons in experimental seizure foci meet both of these criteria: they characteristically exhibit prolonged depolarizations known as paroxysmal depolarization shifts, which in turn trigger trains of action potentials $(4,11)$. Thus, the selectivity of DPH for seizure foci can be interpreted in terms of the modulated receptor $(14,15)$ or

Address reprint requests to Dr. Marban, Department of Medicine, Division of Cardiology, The Johns Hopkins School of Medicine, Hunterian 116, 725 North Wolfe Street, Baltimore, MD 21205.

Received for publication 18 October 1989 and in revised form 28 December 1988.

1. Abbreviations used in this paper: DPH, diphenylhydantoin; TTX, tetrodotoxin.

J. Clin. Invest.

(c) The American Society for Clinical Investigation, Inc. 0021-9738/89/05/1724/09 \$2.00

Volume 83, May 1989, 1724-1732 guarded receptor (16) hypotheses, which postulate preferential binding of the blocker to the inactivated or open states of the $\mathrm{Na}$ channel. This conceptual framework has proven to be of great utility in understanding not only anticonvulsant, but also antiarrhythmic drug action (15). Nevertheless, voltage-dependent block by antiepileptic or antiarrhythmic agents has not been demonstrated to occur in $\mathrm{Na}$ channels of human origin. Qualitative and quantitative differences in Na channels among various species and tissues makes extrapolation of data from animal models to humans difficult. The lack of ready, reproducible access to human tissue has hampered the electrophysiologic and pharmacologic characterization of sodium channels from human brain.

In order to study the effect of DPH on human central nervous system $\mathrm{Na}$ channels, we have extracted total RNA from human brain and injected it into Xenopus oocytes. The oocyte system has been used extensively to study voltage-dependent $\mathrm{Na}$ channels expressed from total RNA, fractions of poly(A) selected RNA (17-22, 27-29), and RNA synthesized in vitro from cDNA (23-26). The expressed channels from neuronal sources have been found to be very similar to those in the primary tissue source (30). We report here the expression of tetrodotoxin-sensitive $\mathrm{Na}$ channels from human brain that are blocked by DPH in a voltage- and use-dependent fashion. These findings are consistent with observations in $\mathrm{Na}$ channels from other mammalian and nonmammalian species, and provide new evidence to support the notion that $\mathrm{Na}$ channel inhibition is an important mechanism of the anticonvulsant effect in patients.

\section{Methods}

The methods used in each experiment are as follows: (a) extraction and purification of RNA from human brain tissue; $(b)$ microinjection of the RNA into Xenopus oocytes, where channel proteins are synthesized and incorporated into the cell surface membrane; and $(c)$ characterization of the expressed channels and analysis of the effect of DPH using the two-microelectrode whole-cell voltage clamp technique. Each step will be described in detail.

$R N A$ extraction and purification. The method used for RNA purification is a modification of that of Auffray and Rougeon (31). Previously frozen samples of cortex from fresh pathological specimens of mid-trimester abortuses were homogenized in $3 \mathrm{M} \mathrm{LiCl}$ and $6 \mathrm{M}$ urea solution to facilitate protein denaturation and RNA precipitation. This was followed by a series of organic extractions and subsequent reprecipitations from ethanol to purify the RNA. Total RNA was stored in aliquots at $-70^{\circ} \mathrm{C}$ at a concentration of $3-4 \mathrm{mg} / \mathrm{ml}$ until microinjection. Consistent and reproducible results were obtained from five different RNA preparations from five distinct tissue specimens.

Oocyte preparation and microinjection. Adult female Xenopus laevis previously injected with human chorionic gonadotropin were purchased from Xenopus One (Ann Arbor, MI). The frogs were anesthetized by immersion in $0.15 \%$ tricaine (3-aminobenzoic acid ethyl ester). Partial oophorectomy was performed through a small abdomi- 
nal incision. The oocytes were manually dispersed in ND-96 solution (32) $(96 \mathrm{mM} \mathrm{NaCl}, 2 \mathrm{mM} \mathrm{KCl}, 1.8 \mathrm{mM} \mathrm{CaCl}, 1 \mathrm{mM} \mathrm{MgCl}$, $5 \mathrm{mM}$ Hepes, pH 7.6) supplemented with $2 \mathrm{mM}$ Na pyruvate, $100 \mathrm{U} / \mathrm{ml}$ penicillin, and $100 \mu \mathrm{g} / \mathrm{ml}$ streptomycin. The oocytes were then rinsed and incubated in a Ca-free saline solution containing $2 \mathrm{mg} / \mathrm{ml}$ collagenase (Type IA; Sigma Chemical Co., St. Louis, MO) for 1-2 h. Individual defolliculated stage V or VI (33) oocytes were selected for microinjection 3-12 h later. Oocytes were injected with $50-100 \mathrm{nl}$ of a solution of RNA (3-4 mg/ml in sterile water) using a $10 \mu \mathrm{l}$ micropipette (Drummond Scientific, Broomall, PA) with a bore pulled to an internal diameter of $20 \mu \mathrm{m}$. Control ("sham-injected") oocytes were injected with a similar volume of sterile water. The oocytes were then incubated for 72-96 h in ND-96 solution, supplemented as described above, until electrophysiologic study.

Electrophysiologic methods and data analysis. Membrane currents were measured using a two-microelectrode voltage clamp (Axoclamp$2 \mathrm{~A}$; Axon Instruments, Burlingame, CA). The bath chamber ( $1 \mathrm{ml} \mathrm{vol}$ ) was continually perfused at a rate of $3 \mathrm{ml} / \mathrm{min}$. The bath solution was a Ca-free modification of ND-96 $(96 \mathrm{mM} \mathrm{NaCl}, 2 \mathrm{mM} \mathrm{KCl}, 2.8 \mathrm{mM}$ $\mathrm{MgCl}_{2}, 5 \mathrm{mM}$ Hepes, $\mathrm{pH} 7.6$ at $22^{\circ} \mathrm{C}$ ) to which drug and toxins were added as indicated. Phenytoin sodium (Parke-Davis Co., Morris Plains, $\mathrm{NJ}$ ), in a vehicle of $40 \%$ propylene glycol and $10 \%$ ethanol, was added to the bath solution to the desired concentration from a stock solution of $50 \mathrm{mg} / \mathrm{ml}$; the final concentrations of propylene glycol and ethanol were $<0.4$ and $0.1 \%$, respectively. Oocytes were bathed in diphenylhydantoin-containing solution for at least $10 \mathrm{~min}$ before recording the DPH-affected currents reported here, though the onset of the effect was rapid and consistent with the perfusion rate.

The current-passing and voltage-recording electrodes were pulled from borosilicate glass (1B150F-6; WP Instruments, Inc., New Haven, CT) to achieve tip resistances of $0.5-1.5 \mathrm{M} \Omega$ and 1-5 $\mathrm{M} \Omega$, respectively, when filled with $3 \mathrm{M} \mathrm{KCl}$.

Current signals were low pass filtered at $1 \mathrm{kHz}$ through an 8-pole Bessel filter (Frequency Devices Inc., Haverhill, MA) and digitized on-line at $5 \mathrm{kHz}$ with 12-bit resolution onto a PDP 11/73 computer (Indec Systems, Sunnyvale, CA). When indicated, the signals were filtered off-line with a digital low pass Gaussian filter. Leak and capacity currents were subtracted using a scaled hyperpolarizing pulse that did not activate any time-dependent ionic currents. Current records are presented in the leak-subtracted format unless otherwise indicated. Peak currents were measured only from traces in which the peak inward current could be clearly distinguished from the capacity transient. When appropriate, currents were normalized to the maximal current elicited for a given test voltage step for inactivation curves or to the peak current in the absence of drug or toxin.

Adequacy of the voltage clamp. Accurate measurement of ionic currents requires adequate voltage control of the preparation. In this study we focus on peak Na currents, recognizing that considerations of spatial voltage control may not allow reliable quantitative analysis of the rapid activation phase of the sodium current. Stage V-VI Xenopus oocytes have a diameter of $1.5 \mathrm{~mm}$ and a surface area of $>25 \mu \mathrm{m}^{2}$, so that voltage control is imperfect even with low-resistance current-passing microelectrodes. Nevertheless, the following considerations argue that the voltage clamp is adequate for measuring peak $\mathrm{Na}$ current. First, there are no "abominable notches" (34) in the current records; second, the increases in the peak $\mathrm{Na}$ current in the negative slope region of the current-voltage curve are graded and parallel in both high and low sodium concentrations (Fig. 2); third, the time to peak current remains constant with increasing current magnitude (Fig. 4) $(34,35)$. We specifically avoided situations in which rapid spatial voltage control of the cell would be critical, such as strong depolarizations (to +20 $\mathrm{mV}$ or higher) during which activation would overlap significantly with the decay of the capacity transient. Thus, the currents used for analysis in this study were generally elicited by depolarizing pulses to negative potentials at or near the peak of the current-voltage relation.

Statistical analysis. The results shown are representative of recordings from 72 human brain-injected oocytes and 18 control oocytes. Pooled data are presented as the mean \pm SEM.

\section{Results}

The results are divided into two sections: the first addresses the issue of the characterization of the expressed channel in human brain RNA-injected oocytes, and the second examines the response of this channel to DPH.

Characteristics of RNA-injected and control oocytes. Injection of RNA from human brain produces a transient inward current not seen in sham-injected cells. Fig. $1 A$ shows the voltage protocol (top) and the raw membrane currents (bottom) elicited by depolarization in a human brain RNA-injected oocyte. The raw currents are composed of a fast capacity transient, which decays in $<5 \mathrm{~ms}$ to reveal an inward current with a sigmoidal onset and exponential decay. The time course of the current varies with the strength of the depolarization. Smaller depolarizations result in currents which peak in 10-20 $\mathrm{ms}$, with stronger depolarizations resulting in larger currents that peak earlier $(<10 \mathrm{~ms})$. The peak inward current varied from oocyte to oocyte, with a range of 100 to $700 \mathrm{nA}$. After the inward current transient has decayed, the current records, particularly at strong depolarizations, reveal an outward current which increases slowly during the voltage pulse.

A

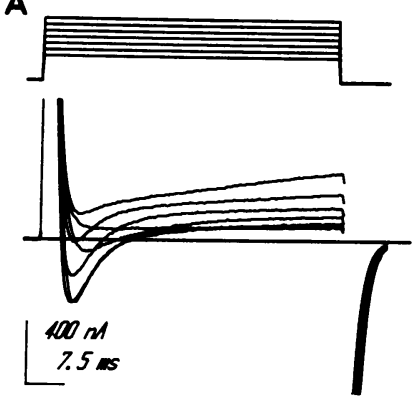

B
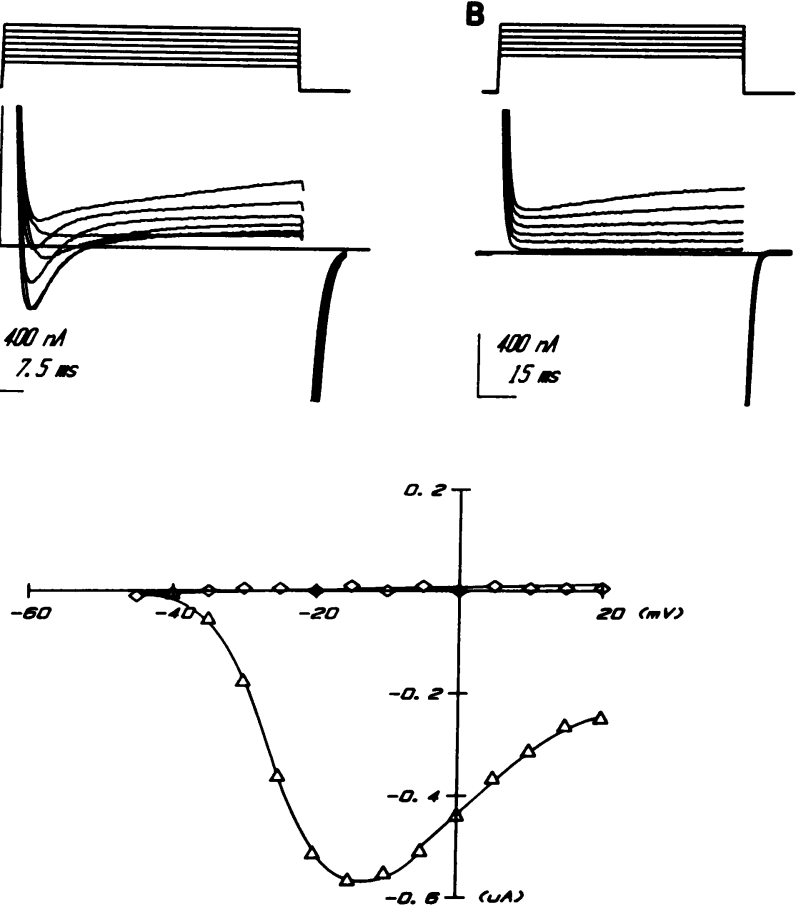

Figure 1. Membrane currents and whole-cell current-voltage relations from representative oocytes bathed in Ca-free ND-96 (see text) depolarized from a holding potential of $-100 \mathrm{mV}$ to various test potentials at a rate of $0.3 \mathrm{~Hz}$. The current records were sampled at 10 $\mathbf{k H z}$, on-line filtered at $2 \mathrm{kHz}$, further off-line filtered at $1 \mathrm{kHz}$ before display. $(A)$ Human brain total RNA-injected oocyte demonstrating a rapidly rising and decaying inward current when depolarized from the holding potential to test potentials of $-40 \mathrm{mV}$ to +20 $\mathrm{mV}$ in increments of $10 \mathrm{mV}$ (cell 062988-3). (B) Sham-injected oocyte revealing a series of time-independent responses to voltage steps from $-40 \mathrm{mV}$ to $+40 \mathrm{mV}$ in increments of $20 \mathrm{mV}$ (cell 093087-2) The records are not leak subtracted to demonstrate the substantial capacity transient and outward currents. $(C)$ The respective currentvoltage relations for the oocytes in $(A)$ and $(B)$ from leak subtracted records, fitted by eye. 
Control, sham-injected oocytes subjected to similar depolarizing voltage pulses (Fig. $1 \mathrm{~B}$ ) reveal only capacity and leak currents over most of the voltage range; at strong depolarizations, a component of time-dependent outward current is also observed.

The outward, slowly developing currents seen in both the RNA-injected and, to a lesser extent, in the control oocytes are at least partially attributable to the calcium-dependent chloride current endogenous to the oocyte $(32,36)$. This interpretation is substantiated by the following observations. The outward current is much larger with Ca-containing bath solutions, particularly in oocytes injected with RNA from excitable tissue; this is the result of $\mathrm{Ca}$ ion flux through endogenous and expressed $\mathrm{Ca}$ channels and subsequent activation of the endogenous chloride current $(32,36)$. In the RNA-injected oocyte, we cannot exclude the possibility that another component of the time-dependent outward current is due to expressed "delayed rectifier" potassium channels. The contribution of these currents to the net membrane current was minimized by working in Ca-free solutions and by avoiding long depolarizing pulses to positive potentials.

As demonstrated in Fig. $1 B$, the control oocytes exhibit no inward current during depolarizing voltage steps. The Xenopus oocyte does contain an endogenous $\mathrm{Na}$ channel, but its voltage- and time-dependence are dramatically different from sodium channels in excitable tissue. The current is induced only after many seconds of depolarization and decays with a similar time course. The sensitivity of the endogenous current to tetrodotoxin (TTX) is five to six orders of magnitude lower than that of expressed channels $(37,38)$. Furthermore, the voltage pulses used here are much too brief to activate this endogenous sodium channel.

We used several criteria to identify the expressed, voltageactivated sodium currents: selectivity for permeant ions, specific pharmacology, and response to voltage changes. The magnitudes of the peak inward currents during steps to various voltages are plotted in Fig. $1 C$ for the human brain RNA-injected oocyte and the sham-injected control. The inward current observed in RNA-injected oocytes begins to activate appreciably at potentials greater than $-40 \mathrm{mV}$ and peaks at approximately $-10 \mathrm{mV}$, suggesting that voltage-dependent $\mathrm{Na}$ channels may be operative. Reliable determination of the reversal potential, which would give an indication of the ionic selectivity of the channel, was not possible because of the rapid time course of the $\mathrm{Na}$ current at very depolarized potentials, the presence of an overlapping outward current, and saturation of the voltage clamp amplifier during large depolarizations. Nevertheless, it is clear that the current would reverse only at quite positive potentials. A value of about $+40 \mathrm{mV}$ is obtained by extrapolation of the current-voltage relation. This value agrees with the Nernst equilibrium potential for $\mathrm{Na}^{+}$ under our ionic conditions (assuming an internal $\mathrm{Na}^{+}$activity of $20 \mathrm{mM}$ [39]).

To bolster our suspicion that the expressed current is carried by $\mathrm{Na}$ ions, we replaced a fraction of the extracellular $\mathrm{Na}^{+}$ with choline ${ }^{+}$, which does not permeate $\mathrm{Na}$ channels (40). Fig. $2 \mathrm{~A}$ shows records of ionic current from a human brain RNAinjected oocyte held at $-90 \mathrm{mV}$ and subjected to a family of depolarizing pulses, shown above the membrane currents, in $96 \mathrm{mM} \mathrm{Na}^{+}$. Fig. $2 \mathrm{~B}$ shows currents in the same oocyte under the same voltage conditions but with $24 \mathrm{mM} \mathrm{Na}^{+}$and $72 \mathrm{mM}$ choline $^{+}$in the bath. As compared with Fig. $2 A$, the inward

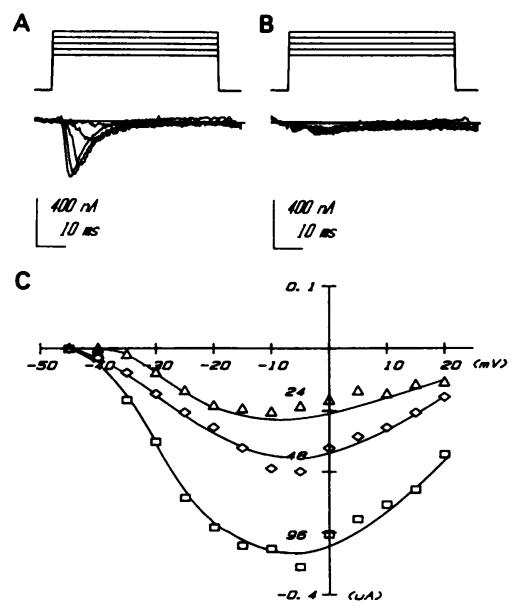

Figure 2. The effect of replacement of $\mathrm{Na}^{+}$ with choline ${ }^{+}$on inward current. The current records are leaksubtracted using a scaled hyperpolarizing pulse as the template. The records are sampled and filtered as described in Fig. 1. $(A)$ The response of an RNA-injected oocyte to a series of depolarizing pulses from a holding potential of $-90 \mathrm{mV}$ to test potentials of -40 $\mathrm{mV}$ to $0 \mathrm{mv}$ in steps of

$10 \mathrm{mV}$ in $96 \mathrm{mM} \mathrm{Na}^{+}$. (B) The same oocyte subjected to the same voltage protocol but in $24 \mathrm{mM} \mathrm{Na}^{+}$and $72 \mathrm{mM}$ choline ${ }^{+}$(cell 071188-4). (C) The current-voltage relations for an oocyte in three different sodium-containing solutions: $96 \mathrm{mM} \mathrm{Na}^{+} 0 \mathrm{mM}^{+}$choline ${ }^{+}$, $48 \mathrm{mM} \mathrm{Na}^{+} 48 \mathrm{mM}$ choline ${ }^{+}, 24 \mathrm{mM} \mathrm{Na}^{+} 72 \mathrm{mM}$ choline ${ }^{+}$(cell 071188-6).

current is dramatically reduced. The effect was fully reversible on return to $96 \mathrm{mM} \mathrm{Na}^{+}$(data not shown). Fig. $2 C$ plots the current-voltage relations from a different oocyte in three different $\mathrm{Na}$ - and choline-containing solutions: $96 \mathrm{mM} \mathrm{Na}^{+}, 0$ $\mathrm{mM}_{\text {choline }}^{+}$; $48 \mathrm{mM} \mathrm{Na}^{+}, 48 \mathrm{mM}_{\text {choline }}^{+}$; and $24 \mathrm{mM} \mathrm{Na}^{+}$, $72 \mathrm{mM}$ choline ${ }^{+}$. As the concentration of sodium in the bath solution decreases, so does the peak inward current at all potentials tested. These results are consistent with the hypothesis that $\mathrm{Na}^{+}$acts as the charge carrier for this current.

$\mathrm{Na}$ channels from excitable tissue are generally quite sensitive to block by TTX, a paralytic poison from the pufferfish. The effect of TTX on the expressed inward current is illustrated in Fig. 3. Fig. $3 \mathrm{~A}$ shows ionic currents from an RNAinjected oocyte that was held at $-80 \mathrm{mV}$ and depolarized in increments of $20 \mathrm{mV}$ to a maximum potential of $+40 \mathrm{mV}$, before exposure to TTX. As Fig. $3 B$ demonstrates, the addition of $150 \mathrm{nM}$ TTX to the bath nearly abolishes the inward current when this oocyte is subjected to the same voltage protocol. The concentration dependence of block of the inward current by TTX is shown in Fig. $3 C$. In this case the oocyte was held at $-100 \mathrm{mV}$ and depolarized to $-10 \mathrm{mV}$ in a series of bath solutions containing progressively higher concentrations of TTX. The peak inward currents in the presence of TTX were normalized to the peak current in the absence of the toxin. The normalized current is a sigmoidal function of the logarithm of toxin concentration consistent with $1: 1$ binding of the toxin to the channel. The data were fit by eye to the equation $\mathrm{I} / \mathrm{I}_{\mathrm{o}}=\mathrm{I}_{\mathrm{o}}\left(1 /\left\{1+K_{\mathrm{d}}[\mathrm{TTX}]\right\}\right)$ where $K_{\mathrm{d}}$ is the halfmaximal blocking concentration ( $46 \mathrm{nM})$. This response, typical of voltage-dependent neuronal sodium channels (41), provides further support for the notion that this is an expressed $\mathrm{Na}$ current.

Further evidence that the expressed channel is indeed a $\mathrm{Na}$ channel comes from the response of the inward current to changes in conditioning potential. Na current can be reduced by changing the holding potential to more depolarized levels, an effect known as steady-state inactivation. Steady-state inactivation results from the voltage-dependent transition of chan- 
A

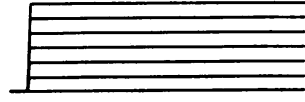

B
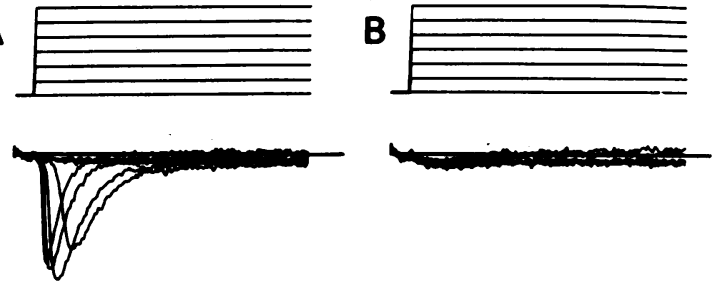

$100 \mathrm{mt}$
$15 \mathrm{~ms}$

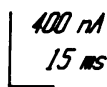

C

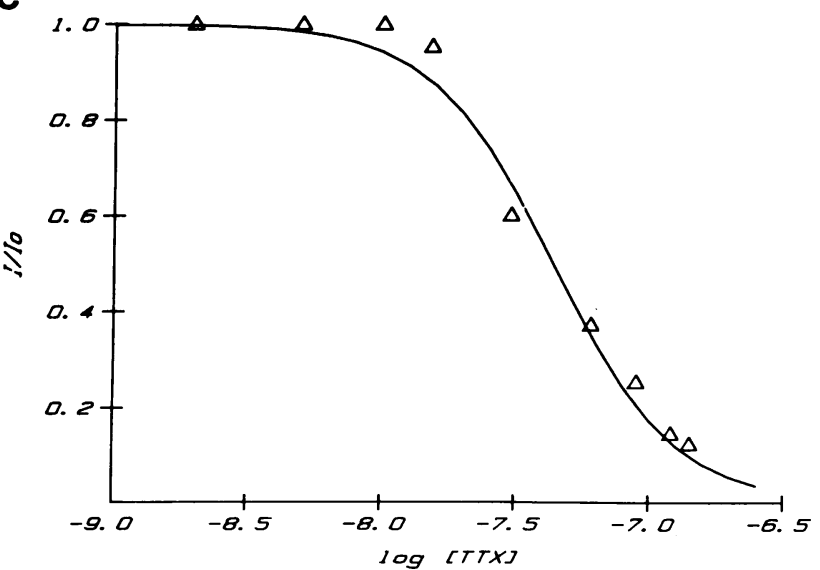

Figure 3. Block of inward current by tetrodotoxin. The current records are acquired and leak-subtracted as previously described. $(A)$ Inward currents from an RNA-injected oocyte at a holding potential of $-80 \mathrm{mV}$ is depolarized in $20 \mathrm{mV}$ increments to a maximum potential of $+40 \mathrm{mV}$ in the absence of toxin. (B) The same oocyte and voltage protocol in the presence of $150 \mathrm{nM}$ tetrodotoxin (cell 022588-4). (C) A typical concentration-response curve for a different oocyte (cell 010188-3). The oocyte is stepped to $-10 \mathrm{mV}$ from a holding potential of $-100 \mathrm{mV}$ in the presence of varing concentrations of tetrodotoxin. The ratio of the peak current in the presence of toxin to that in the absence of toxin $\left(\mathrm{I} / \mathrm{I}_{\mathrm{o}}\right)$ is plotted against the log of the concentration of tetrodotoxin. The data are fit as described in the text, the apparent $K_{\mathrm{d}}$ is $46 \mathrm{nM}$.

nels from a resting (available) to an inactivated (unavailable) state; fewer channels are available to activate during a depolarizing pulse. This effect is apparent in the current records shown in the inset to Fig. 4, obtained from an oocyte voltageclamped at different holding potentials and then depolarized to a fixed test potential of $-10 \mathrm{mV}$. In order to ensure that steady state has been reached, the oocyte is held at each conditioning potential for $30 \mathrm{~s}$ before the application of the test pulse. The peak inward current is normalized to the maximal peak inward current observed for this soltage protocol and plotted against holding potential, in what is traditionally called an $h_{\infty}$ curve (42). The data points are fit by eye to the $h_{\infty}$ parameter, which is described by the function $h_{\infty}=1$ / $\left(1+\exp \left(\mathrm{V}_{\mathrm{h}}-\mathrm{V}_{1 / 2}\right) / K\right.$, where $\mathrm{V}_{\mathrm{h}}$ is the holding potential, $\mathrm{V}_{1 / 2}$ is the potential at which the current is half-maximal, and $K$ is the slope factor. The parameters $\mathrm{V}_{1 / 2}$ and $K$ that describe the curve are -64 and $-6 \mathrm{mV}$, respectively, for this oocyte. For 13 oocytes examined in this fashion, the pooled $\mathrm{V}_{1 / 2}$ and $K$ equaled $-59.7 \pm 4.7 \mathrm{mV}$ and $-6.1 \pm 0.9 \mathrm{mV}$, respectively. Once again, this response is characteristic of voltage-dependent $\mathrm{Na}$ channels.

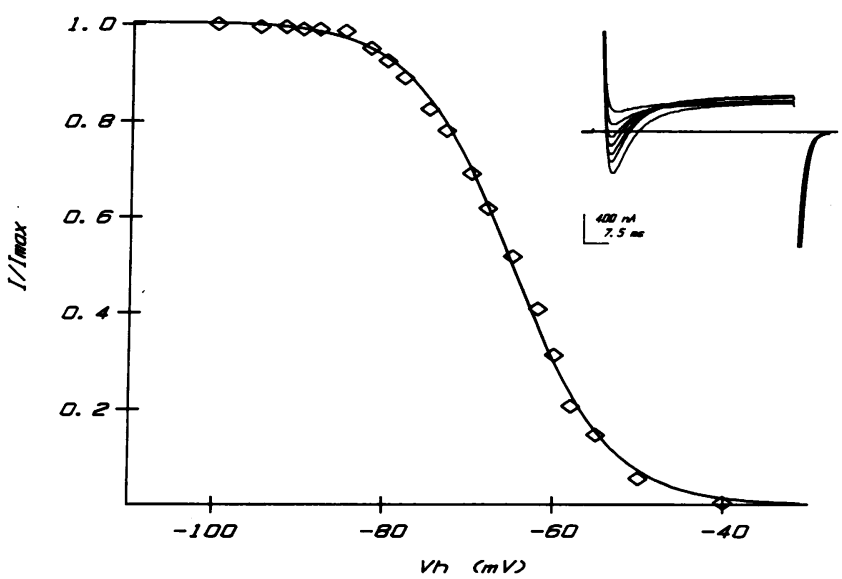

Figure 4. The effect of changes in holding potential on the expressed inward current in human brain RNA-injected oocytes. The oocyte is held at each holding potential for at least $30 \mathrm{~s}$ and then depolarized to $-10 \mathrm{mV}$. The ratio of the peak inward current from each holding potential to the maximal inward current $\left(I / I_{0}\right)$ is plotted against the holding potential (steady-state inactivation curve). The data are fit as described in the text. The potential at which the current is half-maxi$\mathrm{mal}(-64 \mathrm{mV})$, and the slope factor $(-6.0)$. The inset shows the membrane current records (not leak-subtracted) corresponding to the voltage steps from the holding potentials $-100,-80,-75,-70,-65$, -60 , and $-55 \mathrm{mV}$ (cell 062988-3).
A

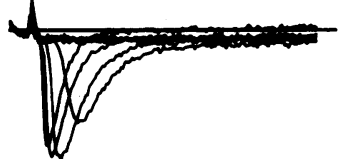

$100 \mathrm{ml}$
$15 \mathrm{~ms}$

C
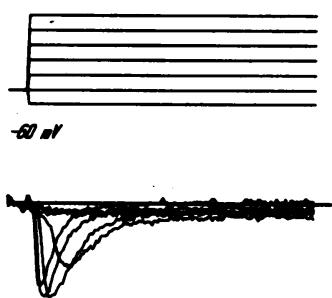

$400 \mathrm{mt}$ $15 \mathrm{~ms}$

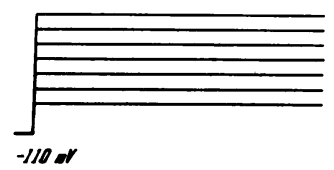

B
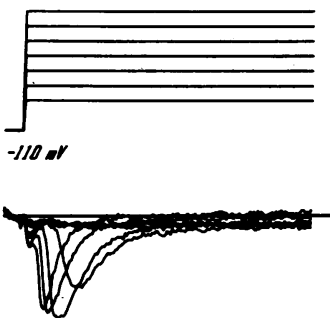

$400 \mathrm{nt}$ $15 \mathrm{~ms}$

D
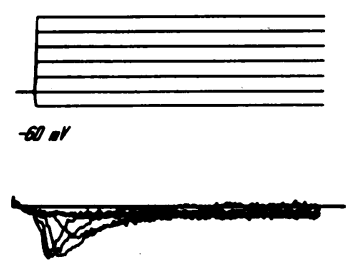

Figure 5. The effect of DPH on peak inward current in human brain RNA-injected oocytes at two different holding potentials. $(A)$ Leak subtracted records of membrane current from a holding potential of $-110 \mathrm{mV}$ to several test potentials. (B) Corresponding membrane currents from the same holding potential in the presence of $100 \mu \mathrm{M}$ DPH. $(C$ and $D)$ Similar current records in the absence and presence of DPH, respectively, from a depolarized holding potential $-60 \mathrm{mV}$. The percentage reduction in peak inward current is more pronounced at the depolarized holding potential, $46 \%$ vs. $18 \%$ (cell 022588-3). 
Effect of DPH on the expressed Na current. We were convinced that we had expressed an exogenous $\mathrm{Na}$ channel from human brain, and sought to examine its pharmacology in more detail. The effect of diphenylhydantoin on $\mathrm{Na}$ channels from other species has been well studied, and its clinical utility motivated us to study its effects on the human channel. To determine whether the mechanism of neuronal $\mathrm{Na}$ channel inhibition described in other mammalian species is relevant to the expressed human channel, oocytes were exposed to DPH, as illustrated in Fig. 5. Membrane currents are shown under their respective voltage protocols. Fig. 5, $A$ and $C$ show the ionic currents in response to a family of depolarizations at 0.3 $\mathrm{Hz}$ from holding potentials of -110 and $-60 \mathrm{mV}$, respectively, in the absence of drug. The oocytes were then exposed to DPH $(100 \mu \mathrm{M})$ and the membrane currents were measured in response to the same voltage steps from the two holding potentials, $-110 \mathrm{mV}(B)$ and $-60 \mathrm{mV}(D)$. Two points are clear from this figure: first, DPH reduces inward current during all depolarizing steps (compare $A$ vs. $B$ and $C$ vs. $D$ ); secondly, the inhibitory effect is considerably potentiated at the more positive holding potential. Compare the currents during voltage steps from the depolarized holding potential, $-60 \mathrm{mV}$, in the absence (C) and presence (D) of DPH, to those from $-110 \mathrm{mV}$ $(A, B)$. During exposure to DPH, the peak current elicited by a voltage step to $-20 \mathrm{mV}$ is reduced by $117 \mathrm{nA}(17 \%)$ at a holding potential of $-110 \mathrm{mV}$, and by $229 \mathrm{nA}(46 \%)$ when the oocyte is held at $-60 \mathrm{mV}$. This effect of conditioning voltage on Na channel inhibition by DPH was seen at all concentrations examined. Fig. 6 shows pooled data for inward currents elicited by depolarizing pulses to $-10 \mathrm{mV}$ from holding potentials of either -100 or $-60 \mathrm{mV}$; all currents are normalized to the peak currents measured at the same voltages in the absence of drug. The normalized currents are plotted against DPH concentration. The percent reduction of inward current is clearly greater from a holding potential of $-60 \mathrm{mV}$ at all concentrations examined.

The voltage-dependent inhibition (block) of the expressed $\mathrm{Na}$ channels by DPH could be relieved by hyperpolarization. This was manifested as a $10 \mathrm{mV}$ hyperpolarizing shift in the $V_{1 / 2}$ of the steady-state inactivation curve by DPH in Fig. 7 . The average $\mathrm{V}_{1 / 2}$ in the absence of drug is $-60 \pm 6 \mathrm{mV}(n=13)$; in the presence of $20-250 \mu \mathrm{M}$ DPH $\mathrm{V}_{1 / 2}$ equals $-69 \pm 5 \mathrm{mV}(n$ $=9$ ). There is also a decrease in the steepness of the curve (i.e., an increase in the absolute value of the slope factor, $K$ ) in the presence of DPH $K$ is $-8 \pm 1 \mathrm{mV}$, the control value of $K$ is $-6 \pm 0.9 \mathrm{mV}$. Qualitatively, these effects are similar to those of

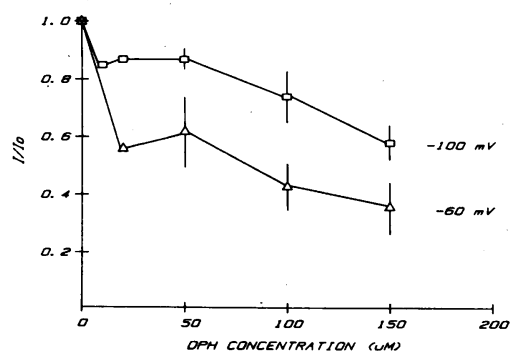

Figure 6. The effect of holding potential on the degree of $\mathrm{Na}$ channel inhibition by DPH over a range of drug concentrations. The graph is a plot of fractional block of inward current $\left(\mathrm{I} / \mathrm{I}_{0}\right)$ against DPH concentration. The currents are elicited by pulses to

$-10 \mathrm{mV}$ from each of the holding potentials. At all concentrations examined the reduction in peak current from a holding potential of $-60 \mathrm{mV}$ (triangles) is greater than that at $-100 \mathrm{mV}$ (squares). Points with error bars represent the means and standard error of the means for three determinations at each potential.

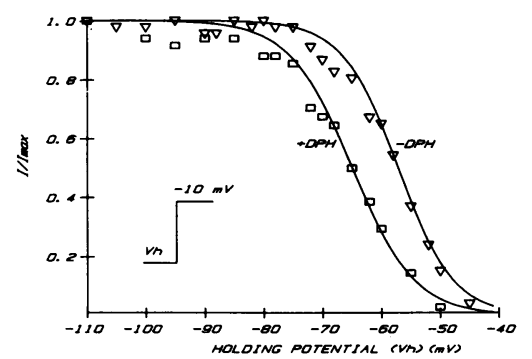

Figure 7. Comparison of the steady state inactivation curves in the presence and absence of DPH. The oocytes are held at various holding potentials and depolarized to $-10 \mathrm{mV}$ as previously described; the relative peak inward current $\left(\mathrm{I} / \mathrm{I}_{\max }\right)$ is plot-

ted against holding potential and fit by the function described in Fig. 4. The currents are normalized to the maximal current under each set of conditions. In the absence of drug (triangles) the $V_{1 / 2}$ is -57 $\mathrm{mV}$ and the slope factor -4.9 compared to the same oocyte in 250 $\mu \mathrm{M} \mathrm{DPH}$ with $\mathrm{V}_{1 / 2}$ of $-67 \mathrm{mV}$ and a slope factor of -6.1 (cell 071188-4). Hyperpolarization in the presence of DPH restored the absolute magnitude of the $\mathrm{Na}$ current to $75 \%$ of that in the absence of drug.

the local anesthetic class of compounds and can be explained by the idea that DPH binds to and stabilizes the inactivated state of the channel.

Use dependence is another characteristic of the inhibition of $\mathrm{Na}$ channels by local anesthetics. That is, repetitive depolarization in the presence of drug increases the block of current by that drug. This effect has been demonstrated in a variety of native preparations of neuronal Na channels exposed to DPH and presumably results from the increased time spent in states that can interact with the drug (inactivated or open). Fig. 8 represents an experiment designed to look for use dependence in our system. After a prolonged rest period ( $>1 \mathrm{~min})$, the oocyte is depolarized from a holding potential of -60 or -100 $\mathrm{mV}$ to $-10 \mathrm{mV}$ at a frequency of $1 \mathrm{~Hz}$. Fig. $8 A$ shows the raw currents elicited by selected depolarizing pulses in the absence of DPH (left), in $200 \mu \mathrm{M}$ DPH from a holding potential of $-100 \mathrm{mV}$ (center), and from a holding potential of $-60 \mathrm{mV}$ in the same concentration of DPH (right). Each set of current records shows the first, second, and thirtieth pulse in the train superimposed. No use dependence is evident in the absence of drug. In the presence of DPH the inhibition of $\mathrm{Na}$ current becomes progressively greater with repetitive depolarizations. The rate of development and the extent of use-dependent inhibition is greater at the depolarized holding potential $(-60$ $\mathrm{mV}$ ). Fig. $8 \mathrm{~B}$ demonstrates this phenomenon graphically. The currents from holding potentials of -100 and $-60 \mathrm{mV}$ are normalized to the current elicited from the first pulse of the train, and are plotted against pulse number. The augmentation of use-dependent block at depolarized potentials probably results from the slower recovery of channels from the inactivated state.

\section{Discussion}

Advantages and limitations of the oocyte expression system in the study of human neuronal Na channels. The electrophysiologic study of $\mathrm{Na}$ channels from mammalian central nervous system tissue is complicated by the fragility and poor viability of cells isolated from the tissue. This problem, compounded by limited availability, is even more acute with human tissue. Much of our knowledge regarding brain $\mathrm{Na}$ channels comes from studies of synaptosomal preparations, field stimulation of brain slices, electrophysiologic study of $\mathrm{Na}$ channels from cultured neuronal cells or peripheral nerve of lower verte- 
A
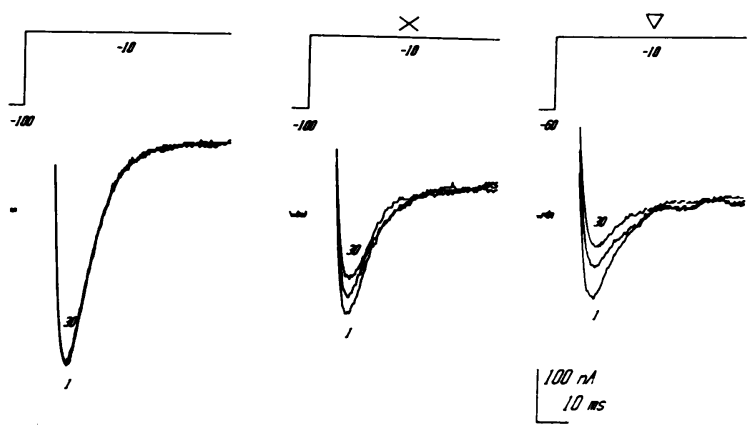

B

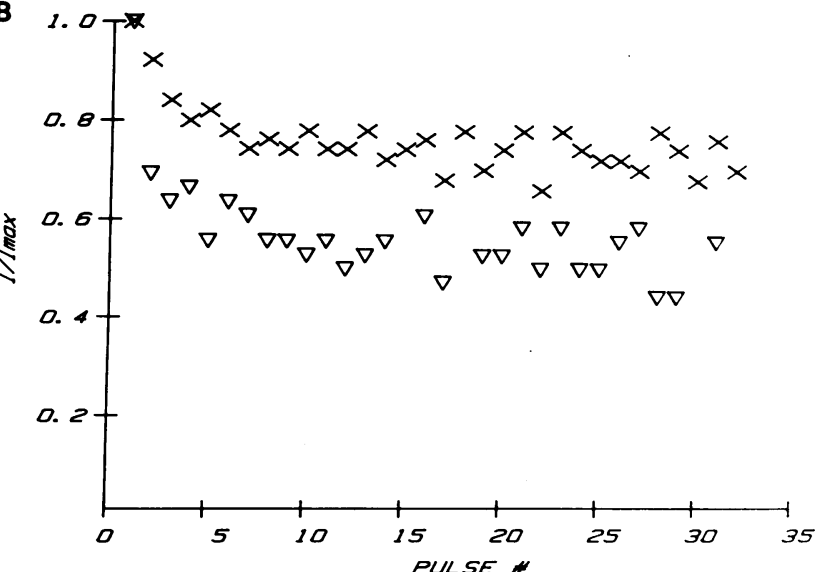

Figure 8. Use-dependent block of Na current by DPH. Human brain RNA injected oocytes were subjected to repeated depolarizations from two different holding potentials, $-60 \mathrm{mV}$ (triangles) and -100 $\mathrm{mV}$ (crosses), at a frequency of $1 \mathrm{~Hz}$ with DPH bath applied to a concentration of $200 \mu \mathrm{M}$. (A) Normalized peak currents (i.e., peak inward current for any given pulse divided by the peak inward current of the first pulse) are plotted against pulse number. $(B)$ The membrane currents for pulses 1,2 , and 30 in the absence of drug from a holding potential of $-100 \mathrm{mV}$ (left, not graphed), from a holding potential of $-100 \mathrm{mV}$ in the presence of DPH (center) and from a holding potential of $-60 \mathrm{mV}$ (right). There is minimal usedependent reduction of current noted in the absence of drug (cell 022588-6). (B) Normalized peak currents $\left(I / I_{\max }\right)$, the peak inward current for any given pulse divided by the peak inward current of the first pulse, are plotted against pulse number.

brates, and channels expressed from nucleic acids in other cell types. These techniques have provided complementary insights into the structure, function, and pharmacology of the various $\mathrm{Na}$ channels. The virtues of using the Xenopus oocyte expression system include the ability to examine ion channels from divergent species and tissues in the same membrane system, and the ability to elucidate the functional importance of subunits of the channel as has been done for the Na channel and nicotinic acetylcholine receptor channel. Of particular importance for the present work is the ability to study channels from an otherwise inaccessible tissue. This unique strength entails a significant limitation; a direct comparison to channels in the intact primary tissue may not be possible, especially in the human case. Thus, it is worth considering the data that have been collected for $\mathrm{Na}$ channels from nonhuman neuronal sources, since a comparison between the source tissue and the oocyte can be made directly.

The electrophysiologic characterization of $\mathrm{Na}$ channels from primary mammalian brain neurons has not been reported, and data on the expressed human brain $\mathrm{Na}$ channel is limited to a single report (18). The mammalian neuronal $\mathrm{Na}$ channel most extensively studied is that of the rat, even in this case studies of the channel in its native membrane are limited to the peripheral nervous system (43).

The Xenopus oocyte expression system has been used extensively to study $\mathrm{Na}$ channels encoded by poly $\mathrm{A}^{+} \mathrm{RNA}(21$, $22)$, fractionated RNA $(21,22,26)$, and four different clones of the $\alpha$ subunit (I, II, IIA, and III) of the $\mathrm{Na}$ channel from rat brain (23-26). Table I summarizes the whole-cell characteristics of activation, inactivation and TTX sensitivity of these preparations. For comparison selected studies of neuronal $\mathrm{Na}$ channels in situ, from cultured neuroblastoma cells, and cultured rat pituitary cells are included, as are the results of this study. Examination of this table reveals reasonable quantitative agreement among the preparations in terms of the TTX sensitivity. Comparison of gating of the expressed channels to native neuronal $\mathrm{Na}$ channels is not straightforward. For example, the rate of inactivation is dependent on the presence of subsidiary (beta) subunits of the channel, as evidenced by slow inactivation in $\mathrm{Na}$ channels expressed from high molecular weight RNA or cDNA of the $\alpha$ subunit $(21-23,25,26)$, and reconstitution of normal inactivation when low molecular weight RNA is added to high molecular weight species (22) or to RNA coding for the $\alpha$ subunit (26). In one circumstance, the same gene product has been examined in the "native" membrane and compared to that expressed in oocytes. In this study the expressed channel demonstrated inactivation, which was shifted $10 \mathrm{mV}$ in the depolarizing direction; importantly, the $\mathrm{Na}$ channel expressed in oocytes was from the cDNA of the $\alpha$ subunit alone, whereas the native channel presumably has its associated $\beta$ subunits (44). In any case, comparison of $\mathrm{Na}$ channels from native preparations to expressed channels reveals a shift of inactivation in the depolarizing direction for the expressed channel. From the comparisons that can be made it appears that the difference between native and expressed channels is quantitative and not qualitative.

We have demonstrated the expression in Xenopus oocytes of $\mathrm{Na}$ channels from total RNA extracted from human brain. Qualitative comparison to expressed $\mathrm{Na}$ channels from other sources of central nervous system tissue $(17-26,28)$ reveals similar current-voltage relations, steady-state inactivation characteristics, and TTX sensitivity (Table I). This suggests that the expressed channel from human brain is functionally intact as are the molecular correlates of the voltage sensor, permeation pathway, and the binding sites for TTX and DPH. Thus, the oocyte expression system is a powerful tool in the study of human ion channels. Nevertheless, the oocyte expression system is not intended to be used to define dose-response relationships or therapeutic concentrations of a drug as they would apply to patients; rather, it is well-suited to mechanistic investigations of drug action on ion channels.

Modification of the expressed human brain Na channel by $D P H$. We have characterized the response of the expressed human channel to DPH, a clinically useful pharmacologic agent whose mechanism of action has been characterized in other systems. DPH is a first-line drug for all forms of epilepsy except absence attacks, and it is the most extensively studied of all the anticonvulsants. DPH has been reported to have effects on several membrane conductance pathways and pumps in neuronal tissue $(1-10,12,13,46,47)$ and other excitable tissue including the heart (48-51). Among the effects of DPH proposed to be mechanistically important in seizure control are 
Table I. Gating Properties and TTX Sensitivity of Expressed and Native Neuronal Na Channels

\begin{tabular}{|c|c|c|c|c|c|c|}
\hline \multirow[b]{2}{*}{ Source (REF) } & \multicolumn{2}{|c|}{ Inactivation } & \multicolumn{2}{|c|}{ Activation } & \multirow[b]{2}{*}{ Voltage of peak $I_{\mathrm{Na}}$} & \multirow[b]{2}{*}{$\mathrm{IC}_{50}$ for TTX } \\
\hline & $V_{1 / 2}$ & $\mathbf{K}$ & $\mathrm{V}_{1 / 2}$ & $\mathbf{K}$ & & \\
\hline & \multicolumn{5}{|c|}{$m V$} & $n M$ \\
\hline \multicolumn{7}{|l|}{ Expressed channels } \\
\hline \multicolumn{7}{|l|}{ Rat brain cDNA } \\
\hline II (23) & -60 & - & - & - & -10 & $10-14$ \\
\hline II (25) & -64 & 10 & -41 & 9 & -14 & - \\
\hline IIA (26) & - & - & - & - & +10 & - \\
\hline III (24) & - & - & -51 & 5 & 0 & 11 \\
\hline \multicolumn{7}{|l|}{ Rat brain RNA } \\
\hline HMW (22) & -34 & 5 & - & - & -10 & 10 \\
\hline poly A (22) & -45 & 8 & - & - & -10 & 23 \\
\hline \multicolumn{7}{|l|}{ Chick brain RNA } \\
\hline poly A (28) & -55 & 5 & - & - & -15 & 5 \\
\hline \multicolumn{7}{|l|}{ Human brain RNA } \\
\hline total (this study) & -60 & 6 & - & - & -10 & 46 \\
\hline \multicolumn{7}{|l|}{ Channels in situ } \\
\hline Rat nerve (43) & -70 & - & -45 & - & -30 & - \\
\hline \multicolumn{7}{|l|}{ Cultured rat pituitary } \\
\hline $\mathrm{GH}_{3}(45)$ & -66 & - & - & - & 0 & - \\
\hline \multicolumn{7}{|c|}{ Cultured mouse neuroblastoma } \\
\hline $\mathrm{N}-18(4)$ & -67 & 3 & 一 & - & +15 & - \\
\hline N1E-115 (3) & -58 & 10 & - & - & +10 & - \\
\hline \multicolumn{7}{|c|}{ Cultured rat pheochromocytoma } \\
\hline PC-12 (44) & -75 & - & -35 & - & -16 & - \\
\hline
\end{tabular}

inhibition of passive $\mathrm{Na}^{+}$influx through ion channels $(1-6$, $8-10,12,13)$, inhibition of $\mathrm{Ca}^{2+}$ influx either directly or indirectly $(2,46,47)$, and alteration of potassium flux $(8)$.

Based on neurochemical and electrophysiological studies in mammalian neurons, inhibition of $\mathrm{Na}$ current has been proposed to be central to the anticonvulsant action of DPH (3, $4,6,9,12,13)$. Furthermore, voltage and use dependence of this inhibition provides an explanation for the minimal interference with normal electrical activity in the brain and minimal sedation caused by DPH at therapeutic doses $(2-4,6)$. Our results are consistent with the hypothesis that the principal antiepileptic action of DPH in humans is its $\mathrm{Na}$ channel blocking activity. The inhibition of the expressed human channel by this agent is both voltage and use dependent, so that DPH preferentially inhibits channels that are depolarized and "used" frequently (as in a seizure focus). Although the dose-response curve has only been preliminarily characterized, an inhibitory effect of DPH on Na current is clearly evident at therapeutically relevant concentrations of 10-20 $\mu \mathrm{M}$ (Fig. 6). The results here confirm and extend those of Matsuki et al. (3) and Willow et al. (4) and suggest that this mechanism of action of DPH may well be operative in human seizure inhibition.

Both use- and voltage-dependent block can be explained in terms of the modulated receptor hypothesis $(14,15)$ or guarded receptor hypothesis (16). In general, voltage- or usedependent inhibition of a channel will arise in the modulated receptor model if the voltage dependence of the transitions of the modified drug-bound channel differs from that of the unmodified channel. In the guarded receptor hypothesis, useand voltage-dependence arise as a consequence of the accessibility of the drug to its binding site. The accessibility is pro- posed to be the major factor that changes with voltage. The effect of DPH on the expressed human $\mathrm{Na}$ channel is consistent with the predictions of both models; our results do not allow us to distinguish between the two.

These models have been applied to $\mathrm{Na}$ channels in other excitable tissues and have proven useful in explaining their inhibition by a number of pharmacologic agents. Most notably, the inhibition of cardiac $\mathrm{Na}$ channels by amine local anesthetics is well described by either the modulated or guarded receptor models $(15,16)$. The effect of DPH on sodium channels from the central nervous system is similar to the effect of lidocaine, a commonly used antiarrhythmic drug, on cardiac $\mathrm{Na}$ channels. In a study of sodium channels from rabbit Purkinje fibers, lidocaine block was demonstrated to be voltagedependent in the steady state, with voltage-dependent recovery from block and use dependence linked to strong binding of the agent to the inactivated state of the channel (52). These findings are remarkably similar to the effects of DPH on human brain $\mathrm{Na}$ channels demonstrated in this study. The mechanism of inhibition of cardiac $\mathrm{Na}$ channels by lidocaine underlies the drug's enhanced binding to rapidly firing, depolarized tissue and hence its antiarrhythmic efficacy. The analogies between arrhythmogenic heart cells and epileptogenic neuronal tissue are clear: both involve foci that are depolarized and firing rapidly, so that in both cases efficacy of $\mathrm{Na}$ channel block by DPH would be enhanced.

\section{Acknowledgments}

We are grateful to Dr. David T. Yue for many helpful discussions and review of the manuscript, and to Dr. Michael White for help in establishing the Xenopus expression system. 
The work has been supported by the Howard Hughes Medical Institute. G. F. Tomaselli is a recipient of a fellowship grant from the American Heart Association, Maryland Affiliate. E. Marban is a recipient of a Research Career Development Award of the NIH (K04 01872).

\section{References}

1. Lipicky, R. J., D. L. Gilbert, and I. M. Stillman. 1972. Diphenylhydantoin inhibition of sodium conductance in squid giant axon. Proc. Natl. Acad. Sci. USA. 69:1758-1760.

2. Perry, J. G., L. McKinney, and P. DeWeer. 1978. The cellular mode of action of the antiepileptic drug 5,5-diphenylhydantoin. $\mathrm{Na}$ ture (Lond.). 272:271-273.

3. Matsuki, N., F. N. Quandt, R. E. Ten Eick, and J. Z. Yeh. 1984 Characterization of the block of sodium channels by phenytoin in mouse neuroblastoma cells. J. Pharmacol. Exp. Ther. 228:523-530.

4. Willow, M., T. Gonoi, and W. A. Catterall. 1985. Voltage clamp analysis of the inhibitory actions of diphenylhydantoin and carbamazepine on voltage-sensitive sodium channels in neuroblastoma cells. Mol. Pharmacol. 27:549-558.

5. Morello, R. S., and T. Begenisich. 1979. Form and site of action of diphenylhydantoin on the sodium channel of squid axons. Biophys. J. 25:135a. (Abstr.)

6. Worley, P. F., and J. M. Baraban. 1987. Site of anticonvulsant action in sodium channels: autoradiographic and electrophysiologic studies in rat brain. Proc. Natl. Acad. Sci. USA. 84:3051-3055.

7. Ranes, A., and F. G. Standaert. 1966. Pre- and postjunctional effects of diphenylhydantoin at the cat soleus neuromuscular junction. J. Pharmacol. Exp. Ther. 153:361-366.

8. Ayala, G. F., S. Lin, and D. Johnston. 1977. The mechanism of action of diphenylhydantoin on invertebrate neurons. I. Effects on basic membrane properties. Brain Res. 121:245-258.

9. McLean, M. J., and R. L. McDonald. 1983. Multiple actions of phenytoin on mouse spinal cord neurons in cell culture. J. Pharmacol. Exp. Ther. 227:779-789.

10. Schwarz, J. R., and W. Vogel. 1977. Diphenylhydantoin: Excitability reducing action in single myelinated nerve fibers. Eur. J. Pharmacol. 44:241-249.

11. Crill, W. 1980. Neuronal mechanisms of seizure initiation. $A d v$. Neurol. 27:169-184.

12. Willow, M., and W. A. Catterall. 1982. Inhibition of binding of $\left[{ }^{3} \mathrm{H}\right.$ ]batrachotoxinin A $20-\alpha$-benzoate to sodium channels by the anticonvulsant drugs diphenylhydantoin and carbamazepine. Mol. Pharmacol. 22:627-635.

13. Willow, M., E. A. Kuenzel, and W. A. Catterall. 1984. Inhibition of voltage-sensitive sodium channels in neuroblastoma cells and synaptosomes by the anticonvulsant drugs diphenylhydantoin and carbamazepine. Mol. Pharmacol. 25:228-235.

14. Hille, B. 1977. Local anesthetics: hydrophilic and hydrophobic pathways for drug-receptor reaction. J. Gen. Physiol. 58:599-619.

15. Hondeghem, L. M., and B. G. Katzung. 1977. Time and voltage dependent interactions of antiarrhythmic drugs with cardiac sodium channels. Biochim. Biophys. Acta. 472:393-398.

16. Starmer, C. F., A. O. Grant, and H. C. Strauss. 1984. Mechanisms of use-dependent block of sodium channels in excitable membranes by local anesthetics. Biophys. J. 46:15-27.

17. Gunderson, C. B., R. Miledi, and I. Parker. 1983. Voltageoperated channels induced by foreign messenger RNA in Xenopus oocytes. Proc. R. Soc. B220:131-140.

18. Gunderson, C. B., R. Miledi, and I. Parker. 1984. Messenger RNA from human brain induces drug and voltage-operated channels in Xenopus oocytes. Nature (Lond.). 308:421-424.

19. Sumikawa, K., I. Parker, and R. Miledi. 1984. Partial purification and functional expression of brain mRNAs coding for neurotransmitter receptors and voltage-operated channels. Proc. Natl. Acad. Sci. USA. 81:7994-7998.

20. Hirono, C., S. Yamagishi, R. Ohara, Y. Hisanaga, T. Na- kayama, and H. Sugiyama. 1985. Characterization of mRNA responsible for induction of functional sodium channels in Xenopus oocytes. Brain Res. 359:57-64.

21. Goldin, A. L., T. Snutch, H. Lubbert, A. Dowsett, J. Marshall, V. Auld, W. Downey, L. C. Fritz, H. A. Lester, R. Dunn, W. A. Catterall, and N. Davidson. 1986. Messenger RNA coding for only the $\alpha$ subunit of the rat brain $\mathrm{Na}$ channel is sufficient for expression of functional channels in Xenopus oocytes. Proc. Natl. Acad. Sci. USA. 83:7503-7507.

22. Krafte, D. S., T. Snutch, J. P. Leonard, N. Davidson, and H. A. Lester. 1988. Evidence for the involvement of more than one mRNA species in controlling the inactivation process of rat and rabbit brain $\mathrm{Na}$ channels expressed in Xenopus oocytes. J. Neurosci. 8:2859-2868.

23. Noda, M., T. Ikeda, H. Suzuki, H. Takeshima, T. Takahashi, M. Kuno, and S. Numa. 1986. Expression of functional sodium channels from cloned cDNA. Nature (Lond.). 322:826-828.

24. Suzuki, H., S. Beckh, H. Kubo, H. Yahagi, H. Ishida, T. Kayano, M. Noda, and S. Numa. 1988. Functional expression of cloned cDNA encoding sodium channel III. FEBS (Fed. Eur. Biochem. Soc.) Lett. 228:195-200.

25. Stühmer, W., C. Methfessel, B. Sakmann, M. Noda, and S. Numa. 1988. Patch clamp characterization of sodium channels expressed from rat brain cDNA. Eur. J. Biophys. 14:131-138.

26. Auld, V. J., A. L. Goldin, D. S. Krafte, J. Marshall, J. M. Dunn, W. A. Catterall, H. A. Lester, N. Davidson, and R. J. Dunn. 1988. A rat brain $\mathrm{Na}^{+}$channel $\alpha$ subunit with novel gating properties. Neuron. $1: 449-461$.

27. Sigel, E. 1987. Properties of single sodium channels translated by Xenopus oocytes after injection with messenger ribonucleic acid. $J$. Physiol. (Lond.). 386:73-90.

28. Sigel, E. 1987. Effects of veratridine on single neuronal sodium channels expressed in Xenopus oocytes. Pfluegers Arch. 410:112-120.

29. Methessel, C., V. Witzemann, T. Takahashi, M. Mishina, S. Numa, and B. Sakman. 1986. Patch clamp measurements on Xenopus laevis oocytes: currents through endogenous channels and implanted acetylcholine receptor and sodium channels. Pfluegers Arch. 407:577588.

30. Lester, H. A. 1988. Heterologous expression of excitability proteins: route to more specific drugs? Science (Wash. DC) 241:1057-1063.

31. Auffray, C., and F. Rougeon. 1980. Purification of mouse immunoglobulin heavy-chain messenger RNAs from total myeloma tumor RNA. Eur. J. Biochem. 107:303-314.

32. Dascal, N., T. P. Snutch, H. Lubbert, N. Davidson, and H. A. Lester. 1986. Expression and modulation of voltage-gated calcium channels after RNA injection in Xenopus oocytes. Science (Wash. DC). 231:1147-1150.

33. Dumont, J. N. 1972. Oogenesis in Xenopus laevis (Daudin). $J$. Morphol. 136:153-180.

34. Colatsky, T. J., and R. W. Tsien. 1979. Electrical properties associated with wide intercellular clefts in rabbit Purkinje fibres. $J$. Physiol. (Lond.). 290:227-252.

35. Colatsky, T. J. 1980. Voltage clamp measurements of sodium channel properties in rabbit purkinje fibers. J. Physiol. (Lond.). 305:215-234.

36. Leonard, J. P., T. P. Snutch, N. Davidson, and H. A. Lester. 1987. Ca channels induced in Xenopus oocytes by rat brain mRNA. $J$. Neurosci. 7:875-881.

37. Baud, C., R. T. Kado, and K. Marcher. 1982. Sodium channels induced by depolarization of the Xenopus laevis oocyte. Proc. Natl. Acad. Sci. USA. 79:3188-3192.

38. Baud, C., and R. T. Kado. 1984. Induction and disappearance of excitability in the oocyte of Xenopus laevis: A voltage-clamp study. J. Physiol. (Lond.). 356:275-289.

39. Kusano, K., R. Miledi, J. Stinnakre. 1982. Cholinergic and catecholaminergic receptors in the Xenopus oocyte membrane. $J$. Physiol. (Lond.). 328:143-170.

40. Hodgkin, A. L., and A. F. Huxley. Currents carried by sodium 
and potassium ion through the membrane of the giant axon of Loligo. 1952. J. Physiol. (Lond.). 116:449-472.

41. Hille, B. 1984. Ionic channels of excitable membranes. Sinauer Associates Inc., Sunderland, MA. 21-75.

42. Hodgkin, A. L., and A. F. Huxley. 1952. A quantitative description of membrane current and its application to conduction and excitation in nerve. J. Physiol. (Lond.). 117:500-544.

43. Neumcke, B., and R. Stämpfli. 1982. Sodium currents and sodium-current fluctuation in rat myelinated nerve fibres. $J$. Physiol. (Lond.). 329:163-184.

44. Mandel, G., S. S. Cooperman, R. A. Maue, R. H. Goodman, P. Brehm. 1988. Selective induction of brain type II $\mathrm{Na}^{+}$channels by nerve growth factor. Proc. Natl. Acad. Sci. USA. 85:924-928.

45. Vandenberg, C., and R. Horn. 1984. Inactivation viewed through single sodium channels. J. Gen. Physiol. 84:535-564.

46. Pincus, J. H., and S. H. Lee. 1973. Diphenylhydantoin and calcium: relation to norepinephrine release from brain slices. Arch. Neurol. 29:239-244.
47. Twombly, D. A., M. Yoshii, and T. Narahashi. 1988. Mechanisms of calcium channel block by phenytoin. J. Pharmacol. Exp. Ther. 246:189-195.

48. Rosen, M. R., P. Danilo, Jr., M. B. Alonso, and C. E. Pippenger. 1976. Effects of therapeutic concentrations of diphenylhydantoin on transmembrane potentials of normal and depressed Purkinje fibers. J. Pharmacol. Exp. Ther. 197:594-604.

49. Peon, J., G. R. Ferrier, and G. K. Moe. 1978. The relationship of excitability to conduction velocity in canine Purkinje tissue. Circ. Res. 43:125-135.

50. Bigger, J. T., and W. J. Mandel. 1970. Effect of lidocaine on the electrophysical properties of ventricular muscle and Purkinje fibers. $J$. Clin. Invest. 49:63-77.

51. Singh, B. N., and E. M. Vaughn Williams. 1971. Effect of altering potassium concentration of the action of Lidocaine and diphenylhydantoin on rabbit atrial and ventricular muscle. Circ. Res. 29:286-295.

52. Bean, B. P., C. J. Cohen, and R. W. Tsien. 1983. Lidocaine block of cardiac sodium channels. J. Gen. Physiol. 81:613-642. 